\title{
A novel pyrido-thieno-pyrimidine derivative activates p53 through induction of phosphorylation and acetylation in colorectal cancer cells
}

\author{
MI AE KANG ${ }^{1}$, MI-SOOK KIM ${ }^{1,2}$, JI YOUNG KIM ${ }^{1}$, YOUNG-JOO SHIN ${ }^{3}$, \\ JIE-YOUNG SONG ${ }^{1,4}$ and JAE-HOON JEONG ${ }^{1}$
}

\author{
${ }^{1}$ Research Center for Radiotherapy, Korea Institute of Radiological and Medical Sciences; \\ ${ }^{2}$ Department of Radiation Oncology, Korea Institute of Radiological and Medical Sciences, Seoul; \\ ${ }^{3}$ Department of Radiation Oncology, Inje University Sanggye Paik Hospital, Seoul; ${ }^{4}$ Division of Radiation \\ Cancer Research, Korea Institute of Radiological and Medical Sciences, Seoul, Republic of Korea
}

Received August 19, 2014; Accepted October 3, 2014

DOI: 10.3892/ijo.2014.2720

\begin{abstract}
The tumor suppressor p53 plays a key role in regulation of the cell cycle, apoptosis and senescence in response to various stresses. We screened a library of 7920 chemical compounds for the p53 activator and identified $\mathrm{N}-[2-$ (dimethylamino)ethyl]-2,3-dimethyl-4-oxo-4H-pyrido[1,2-a] thieno[2,3-d]pyrimidine-9-carboxamide (PTP), which significantly increased p53-mediated reporter activity in colorectal cancer cells. PTP was found to induce $\mathrm{p} 53$ protein and activated transcription of downstream genes, such as p21 and PUMA, in HCT116 cells, leading to growth delay, G1-phase cell cycle arrest, cell senescence and cell death. Proximity ligation assay revealed that PTP weakened the interaction between p53 and murine double minute 2 (MDM2) in situ, thereby inhibiting MDM2-mediated p53 degradation. Although DNA damage has been known to promote phosphorylation of p53 and MDM2, thereby preventing their interaction and stabilizing p53, PTP did not cause DNA damage or activate any DNA damage response signaling. Instead, phosphorylation of p53 was mediated by Erk1/2 MAP kinase. In addition, PTP induced acetylation of p53 at Lys382 in a p300-dependent manner, but sirtuin (SIRT)1 and histone deacetylase (HDAC)1,
\end{abstract}

Correspondence to: Dr Jae-Hoon Jeong, Research Center for Radiotherapy, Korea Institute of Radiological and Medical Sciences, 75 Nowon-ro, Nowon-Gu, Seoul 139-706, Republic of Korea E-mail: jeongj@kirams.re.kr

Dr Jie-Young Song, Division of Radiation Cancer Research, Korea Institute of Radiological and Medical Sciences, 75 Nowon-ro, Nowon-Gu, Seoul 139-706, Republic of Korea

E-mail:immu@kirams.re.kr

Abbreviations: PTP, N-[2-(dimethylamino)ethyl]-2,3-dimethyl-4oxo-4H-pyrido[1,2-a]thieno[2,3-d]pyrimidine-9-carboxamide

Key words: p53, phosphorylation, acetylation, MDM2, ERK1/2, p300, colorectal cancer a well-known p53-regulating deacetylase, were not involved. In the present study, the novel anticancer agent PTP was shown to cause the accumulation of p53 by inducing multiple post-translational modifications, as well as cell cycle arrest, senescence and cell death.

\section{Introduction}

The tumor suppressor p53 plays a key role in regulation of the cell cycle, apoptosis, DNA repair, and senescence in response to various acute stresses, such as DNA damage, hypoxia, changes in redox potential and abnormal expression of oncogenes $(1,2)$. Activation of p53 after DNA damage affects genes associated with cell cycle arrest, DNA repair and apoptosis, including p21, Bax, PUMA and murine double minute 2 (MDM2) $(3,4)$. In addition to its role as a transcriptional activating protein, p53 also serves as a negative transcription factor, downregulating the expression of genes, such as the anti-apoptotic gene bcl-2 (5).

The regulation of p53 activity is mostly through posttranslational modification. Stabilization is an essential step for efficient functioning of p53 in response to cellular stresses. Under physiological conditions, p53, in most cells, is expressed at a low or undetectable level, with a half-life of a few minutes. This rapid degradation is, at least in part, mediated by the ubiquitination pathway following the interaction of MDM2 with the N-terminus of $\mathrm{p} 53$. Under a condition of stress, such as DNA damage caused by ionizing radiation or cytotoxic agents, endogenous p53 is stabilized through a series of physiological responses, including ataxia telangiectasia mutated (ATM)/ATM and Rad3-related (ATR) activation (6,7), phosphorylation and acetylation of $\mathrm{p} 53$, and weakening of the binding of MDM2 to p53.

Because of the strong possibility of p53 eliciting apoptosis or growth arrest in cells, pharmacological reactivation of the p53 tumor suppressor is a promising strategy for anticancer therapy. Previous studies showed that some small compounds induce cancer cell cycle arrest and apoptosis through restoration of the p53 pathway $(8,9)$. Some other molecules were also 
identified that induce the activity of p53, which effectively represses angiogenesis (10) and the growth of xenograft tumors (11).

Pyrimidine derivatives are well known for their pharmacological activities. Various drugs containing a pyrimidine nucleus are synthesized and used as anticancer drugs; these include 5-fluorouracil (5-FU), tegafur and thioguanine (12). Other pyrimidine derivatives, such as 2-cyanopyrimidines (13), hydrazinopyrimidine-5-carbonitriles (14), and some series of $\mathrm{N}$-(2-(trifluoromethyl)pyridin-4-yl) anthranilic acids, show antiproliferative activity against human cancer cells (15). 5 -FU is the optimal choice of all chemotherapeutic agents when treating patients with colorectal cancer. Intracellular metabolites of 5-FU can exert cytotoxic effects via inhibition of thymidylate synthetase or incorporation into DNA or RNA, events that ultimately activate apoptosis (16).

We sought to develop a new agent capable of activating p53 that could be used as an anticancer agent (17). In our process, we screened a chemical-compound library for p53 activators and identified N-[2-(dimethylamino)ethyl]-2,3-dimethyl-4oxo-4H-pyrido[1,2-a]thieno[2,3-d]pyrimidine-9-carboxamide (PTP), which significantly increased p53 reporter activity. In the present study, we identified PTP as a novel activator of the p53 response and characterized its antitumor mechanism in human colorectal cancer cells.

\section{Materials and methods}

Cells and reagents. The human colorectal adenocarcinoma cancer cell lines HCT116 and HT-29 were obtained from the Korean Cell Line Bank (KCLB, Seoul, Korea). All cells were maintained in RPMI-1640 medium (PAA Laboratories, Pasching, Austria) supplemented with $10 \%$ heat-inactivated fetal bovine serum (PAA Laboratories) and $100 \mathrm{U} / \mathrm{ml}$ penicillin/streptomycin. PTP was obtained from ChemBridge (San Diego, CA, USA). U-0126 was purchased from Assay Designs (Ann Arbor, MI, USA); anacardic acid was from Santa Cruz Biotechnology (Santa Cruz, CA, USA).

Luciferase assay. HCT116 cells were transfected with the p53-Luc reporter vector using Lipofectamine 2000 (Invitrogen, Carlsbad, CA, USA) according to the manufacturer's instructions, and stably transfected cell lines were established by selection in medium containing G418 $(1 \mathrm{mg} / \mathrm{ml})$. The cells were inoculated into duplicate 96-well plates at 15,000 cells/well, incubated for $24 \mathrm{~h}$, and then treated for an additional $24 \mathrm{~h}$ with each of the 7920 small-molecule compounds at a final concentration of $10 \mu \mathrm{M}$. The cells were then washed with phosphate-buffered saline (PBS) and lysed in $100 \mu \mathrm{l}$ cell lysis buffer (Promega, Madison, WI, USA), after which p53-dependent luciferase activity was determined using a Luciferase Assay kit (Promega).

RNA isolation and real-time PCR. Total RNA was isolated using the Hybrid-R Total RNA purification kit (GeneAll, Seoul, Korea). One microgram of total RNA was reverse transcribed with PrimeScript RT Master Mix (Takara Bio, Shiga, Japan). After 1:10 dilution, $2 \mu \mathrm{l}$ cDNA was used as template in a 20- $\mu$ l PCR reaction mixture. Real-time PCR was performed using qPCR SYBR-Green Master Mix (MBiotech, Seoul,
Korea) on a CFX96 Real-Time PCR Detection system (BioRad Laboratories, Hercules, CA, USA). The following primers were used for real-time PCR: p21 (5'-CTGCGCCAGCTG AGGTGTGAG-3' and 5'-GCCGCATGGGTTCTGACGGA-3'); PUMA (5'-CCTGGAGGGTCCTGTACAATCT-3' and 5'-GC ACCTAATTGGGCTCCATCT-3'); CYPA (5'-CCCACCG TGTTCTTCGACAT-3' and 5'-CCAGTGCTCAGAGCACG AAA-3'); RPL13A (5'-CCTGGAGGAGAAGAGGAAAG AGA-3' and 5'-TTGAGGACCTCTGTGTATTTGTCAA-3'). The relative quantification of gene expression was carried out using the $\Delta \Delta \mathrm{Ct}$ method and CFX Manager Software (Bio-Rad Laboratories) with multiple reference genes (CYPA and RPL13A). The PCR program was as follows; initial denaturation at $95^{\circ} \mathrm{C}$ for $10 \mathrm{~min}$ followed by 45 cycles, of $95^{\circ} \mathrm{C}$ for $5 \mathrm{sec}$ and $60^{\circ} \mathrm{C}$ for $30 \mathrm{sec}$. The last amplification cycle was followed by a melt curve analysis to confirm the specificity of the PCR amplification.

Fluorescence-activated cell sorting (FACS) analysis. The cells were harvested by trypsinization, fixed by overnight incubation in $70 \%$ ethanol at $-20^{\circ} \mathrm{C}$, stained with propidium iodide (50 $\mu \mathrm{g} / \mathrm{ml}$ ) containing $50 \mu \mathrm{g} / \mathrm{ml}$ RNase A (Sigma-Aldrich, St. Louis, MO, USA), and the cell death and cell cycle profile was analyzed by flow cytometry. Cell death was measured as the percentage of cells in the sub-G1 population.

Senescence-associated (SA) $\beta$-galactosidase assay. HCT116 cells $\left(5 \times 10^{4}\right)$ were plated in $35-\mathrm{mm}$ culture dishes and treated with 0,5 and $10 \mu \mathrm{M}$ PTP for 6 days. Cells were fixed in $2 \%$ formaldehyde $/ 0.2 \%$ glutaraldehyde for $5 \mathrm{~min}$ at room temperature, and SA $\beta$-galactosidase staining was performed according to the manufacturer's instructions (Cell Signaling Technology, Danvers, MA, USA).

Cell viability and proliferation assay. HCT116 and HT-29 cells $\left(2 \times 10^{3}\right)$ were plated in 96 -well plates and allowed to attach for $24 \mathrm{~h}$ prior to treatment. The cells were exposed to various concentrations of PTP for $48 \mathrm{~h}$, and cell viability was evaluated using the Ez-Cytox Cell viability, Proliferation \& Cytotoxicity Assay kit (Daeil Lab Service, Seoul, Korea) according to the manufacturer's instructions.

Immunofluorescence. Cells cultured on 18x18-mm cover glasses were fixed in $4 \%$ paraformaldehyde for $10 \mathrm{~min}$, permeabilized with $1 \%$ Triton $\mathrm{X}-100$ for $5 \mathrm{~min}$, and then blocked in PBS containing 10\% FBS for 30 min. Cells were incubated with anti- $\gamma-\mathrm{H} 2 \mathrm{AX}$ antibody (Millipore, Billerica, MA, USA) overnight at $4^{\circ} \mathrm{C}$ and then with FITC-conjugated secondary antibodies (Invitrogen) for $1 \mathrm{~h}$ at room temperature. After counterstaining with 4',6-diamidino-2-phenylindole (DAPI), immunofluorescence images were captured with a laser-scanning confocal microscope (LSM710; Carl Zeiss MicroImaging, Jena, Germany).

Western blot analysis. Cells were lysed in radioimmunoprecipitation assay (RIPA) buffer [50 mM Tris-Cl ( $\mathrm{pH} 8.0)$, $150 \mathrm{mM} \mathrm{NaCl}, 0.1 \%$ SDS, $0.5 \%$ deoxycholic acid, 1\% NP-40], and protease inhibitor and phosphatase inhibitor cocktail and briefly sonicated. Protein content was measured using the Coomassie (Bradford) Protein Assay kit (Thermo Fisher 

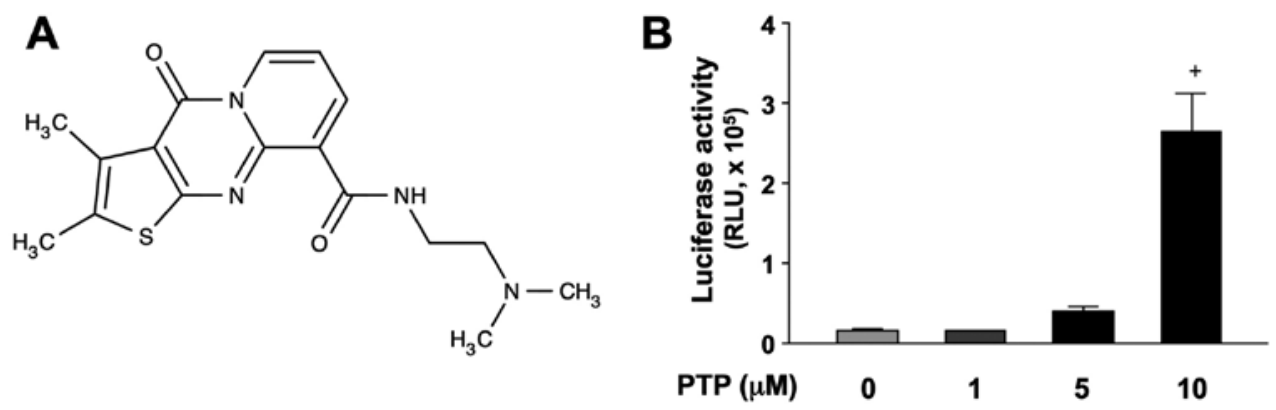

Figure 1. PTP increases p53 reporter activity. (A) Structure of PTP (N-[2-(dimethylamino)ethyl]-2,3-dimethyl-4-oxo-4H-pyrido[1,2-a]thieno[2,3-d]pyrimidine9-carboxamide). (B) HCT116 cells stably transfected with p53-Luc plasmid were treated with the indicated amount of PTP. After $24 \mathrm{~h}$, luciferase activity was measured.

Scientific, Rockford, IL, USA) and equal amounts of cell lysates were separated on SDS-polyacrylamide gels and transferred to nitrocellulose membranes (Bio-Rad Laboratories). Membranes were immunoblotted with antibodies against p53, p21, cyclin D1, cyclin E, cyclin A, p300, $\beta$-actin (Santa Cruz Biotechnology), phospho-p53 (Ser15), acetyl-p53 (Lys382), phospho-Chk2 (Thr68), Erk1/2, phospho-Erk1/2, phospho-JNK, phospho-p38 (Cell Signaling Technology), phospho-ATM (Ser1981), Chk2, $\gamma$-H2AX (Ser139) (Millipore), ATM (Epitomics, Burlingame, CA, USA) and chemiluminescence was detected using ECL detection reagents.

Small interfering RNAs (siRNAs). The siRNA duplexes with the following sequences were synthesized by Genolution Pharmaceuticals, Inc. (Seoul, Korea): Erk1 (5'-UUAGAGAGC AUCUCAGCCAGAAUGC-3'), Erk2 (5'-AAGAGGAUUGA AGUAGAACAGdTdT-3'), and p300 (5'-AACCCCUCCUC UUCAGCACCAdTdT-3'). Cells in 60-mm culture plates were transfected with $20 \mathrm{nM}$ siRNA oligonucleotides using Lipofectamine RNAiMAX reagent (Invitrogen) according to the manufacturer's instructions.

In situ proximity ligation assay (PLA). In situ PLA was performed according to the manufacturer's instructions (Olink Bioscience, Uppsala, Sweden). Briefly, cells cultured on $18 \times 18-\mathrm{mm}$ cover glasses were fixed in $4 \%$ paraformaldehyde for $10 \mathrm{~min}$, permeabilized with $1 \%$ Triton X-100 for $5 \mathrm{~min}$, and then blocked for $30 \mathrm{~min}$ at $37^{\circ} \mathrm{C}$. Cells were incubated with anti-p53 antibody (Santa Cruz Biotechnology) together with anti-MDM2, anti-p300, anti-histone deacetylase (HDAC)1 (Santa Cruz Biotechnology), or anti-sirtuin (SIRT)1 antibody (Millipore) overnight at $4^{\circ} \mathrm{C}$. After removal of unbound primary antibodies, cells were incubated with proximity probes (antirabbit PLUS and anti-mouse MINUS) (Olink Bioscience) for $1 \mathrm{~h}$ at $37^{\circ} \mathrm{C}$. The ligation reaction was performed for $30 \mathrm{~min}$ at $37^{\circ} \mathrm{C}$ followed by polymerization reaction for $2 \mathrm{~h}$ at $37^{\circ} \mathrm{C}$. The cells were counterstained with DAPI, and immunofluorescence images were captured with a laser-scanning confocal microscope.

\section{Results}

PTP increases p53 luciferase activity. The tumor suppressor p53 is involved in multiple cellular processes and is a good molecular target for cancer therapy. To identify novel chemo- therapeutic agents that activate the p53 response, a p53-dependent promoter-luciferase reporter system was developed. Small-molecule compounds in a chemically diverse library, dissolved in DMSO at $10 \mu \mathrm{M}$, were assayed in a 96-well format in duplicate in order to measure p53-dependent transactivation. In an initial screen using a luciferase assay, we selected 26 of the 7920 tested molecules on the basis of a $>2$-fold increase in activity. One of the positive compounds, $\mathrm{N}$-[2-(dimethylamino)ethyl]-2,3-dimethyl-4-oxo-4Hpyrido[1,2-a]thieno[2,3-d]pyrimidine-9-carboxamide (PTP), structure of which is shown in Fig. 1A, significantly increased p53-luciferase activity in HCT116 cells in a concentrationdependent manner (Fig. 1B).

PTP increases wild-type $p 53$ protein and induces $p 53$ target gene expression. To verify the effect of PTP on $\mathrm{p} 53$ activation in vivo, two colon cancer cell lines were treated with PTP. As shown in Fig. 2A, treatment with $10 \mu \mathrm{M}$ PTP increased the p53 protein level in a time-dependent manner in HCT116 cells expressing wild-type p53. To confirm the activity of induced $\mathrm{p} 53$, we examined the expression of the p53-target genes, p21 and PUMA. Both transcript and protein levels of p21 were increased by PTP in a time- (Fig. 2A) and dosedependent manner (Fig. 2B). Also, the level of PUMA mRNA was increased dose-dependently (Fig. 2B). However, in HT-29 cells that harbor p53 mutation, PTP did not affect either the protein level of $\mathrm{p} 53$ or the induction of p21 or PUMA (Fig. 2A and B). The p53 protein is maintained at a very low level in unstressed cells, and this level is determined by its rate of degradation rather than transcription or translation. This degradation is ensured by negative feedback regulation due to an ubiquitin ligase, MDM2 $(18,19)$. To determine the cause of the PTP-mediated p53 accumulation, we investigated the interaction of $\mathrm{p} 53$ and MDM2 in PTP-treated HCT116 cells by in situ PLA. As Fig. 2C shows, in the presence of MG132, an inhibitor of proteasomal degradation, interaction between p53 and MDM2 was increased by 8.2-11.9-fold compared with untreated cells. However, this increase of p53-MDM2 interaction was suppressed in cells treated with PTP or the MDM2 antagonist nutlin-3a. These results suggest that PTP-induced p53 accumulation is due to suppression of p53-MDM2 interaction.

PTP induces p53-dependent G1-phase cell cycle arrest and senescence. The effect of PTP on cell cycle progression 
A

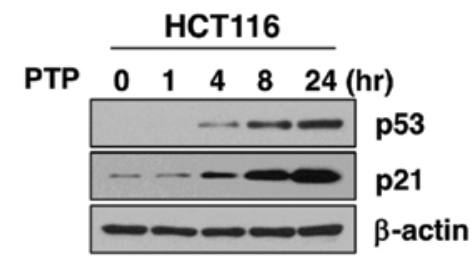

B

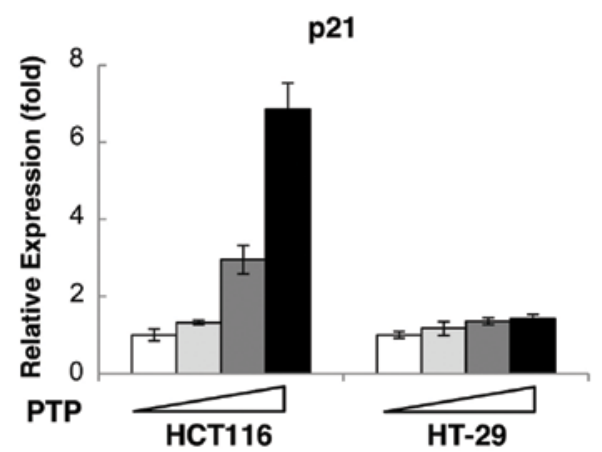

C

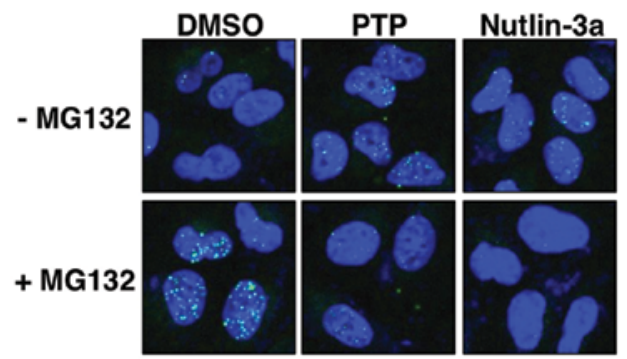

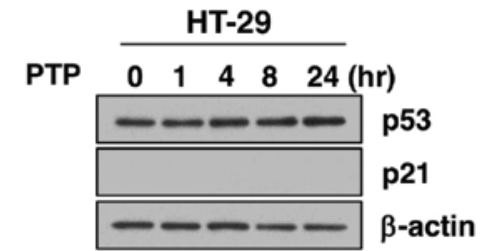

PUMA
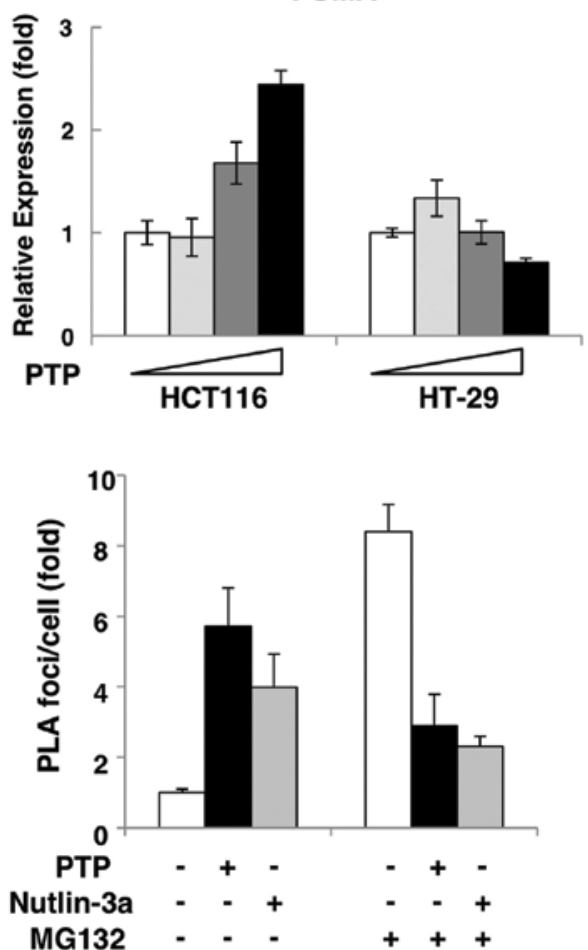

Figure 2. PTP induces increases in p53 protein level and transcriptional activity. (A) HCT116 and HT-29 cells were treated with $10 \mu \mathrm{M}$ PTP for the indicated times. The levels of p53 and p21 were detected by western blot analysis with specific antibodies. $\beta$-actin was used as the loading control. (B) HCT116 and HT-29 cells were treated with $0,2,5$ and $10 \mu \mathrm{M}$ increasing concentrations of PTP for $8 \mathrm{~h}$. Total cellular RNA was prepared and expression of p21 and PUMA was examined by qRT-PCR. (C) Interaction between p53 and MDM2 was examined by in situ PLA. HCT116 cells were treated with $10 \mu \mathrm{M}$ PTP and $10 \mu \mathrm{M}$ nutlin-3a in the presence or absence of $5 \mu \mathrm{M} \mathrm{MG132}$ for $8 \mathrm{~h}$, and the assay was performed according to the manufacturer's instructions.

was examined by flow cytometric analysis of PTP-treated HCT116 and HT-29 cells (Fig. 3A). The cell cycle analysis revealed that HCT116 cells were arrested at the G1 phase of the cell cycle after $24 \mathrm{~h}$ of exposure to $10 \mu \mathrm{M}$ PTP, but the cell cycle distribution of HT-29 cells was unchanged. The levels of cyclin D1 and cyclin E (markers of G1 phase) increased time-dependently, and cyclin A (marker of S phase) decreased after $24 \mathrm{~h}$ (Fig. 3B). As cell cycle arrest in G1-phase led to premature senescence, we carried out SA $\beta$-galactosidase assay to determine if long-term exposure to PTP could induce senescence of HCT116 cells. As shown in Fig. 3C, SA $\beta$-galactosidase-stained HCT116 cells increased by 4.3 - and 6.7-fold after treatment with 5 and $10 \mu \mathrm{M}$ PTP, respectively, for 6 days. These results suggest that PTP induces G1 phase cell cycle arrest and leads to premature senescence in cancer cells through a p53-dependent mechanism.

PTP suppresses proliferation and induces cell death of HCT116 cells. Cell viability assay was performed in PTP-treated HCT116 and HT-29 cells to determine the effect of PTP on proliferation of colon cancer cells. Fig. 4A shows that the growth of HCT116 cells treated with 5 and $10 \mu \mathrm{M}$ PTP was markedly inhibited. However, there was no significant growth inhibition of HT-29 cells treated with $5 \mu \mathrm{M}$ PTP. To examine if PTP caused cell death, we performed flow cytometric analysis of PTP-treated HCT116 and HT-29 cells. The cell cycle analysis showed that HCT116 cells appeared to undergo cell death after $64 \mathrm{~h}$ of exposure to PTP, as evidenced by the accumulation of sub-G1 cells. In contrast, no sub-G1 accumulation was observed in PTP-treated HT-29 cells (Fig. 4B).

PTP induces phosphorylation of p53 irrespective of DNA damage. We originally speculated that PTP might act as a DNA-damaging agent. The DNA damage signal cascade was confirmed after treatment of HCT116 cells with PTP. HCT116 cells were treated with $10 \mu \mathrm{M}$ PTP for $0,1,4,8$ or $24 \mathrm{~h}$. Cell lysates were subjected to SDS-PAGE and probed with antibodies against proteins in the DNA damage signal cascade. To prepare a DNA damage control sample, HCT116 cells were irradiated at $5 \mathrm{~Gy}$ and harvested after $1 \mathrm{~h}$. As shown in Fig. 5A, PTP exposure and $\gamma$-irradiation induced phosphorylation of p53 at Ser15. However, PTP treatment did not lead to phosphorylation of ATM (Ser1981), Chk2 (Thr68), or H2AX (Ser139), whereas $\gamma$-irradiation did. Together with 
A

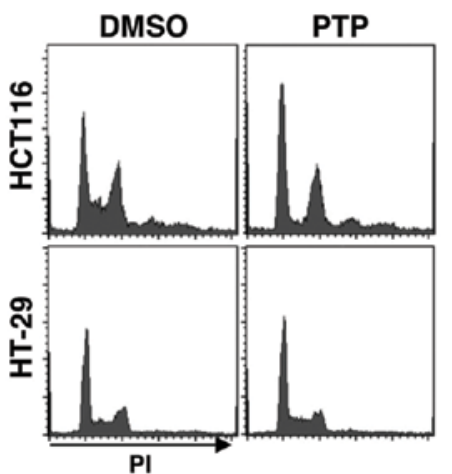

C

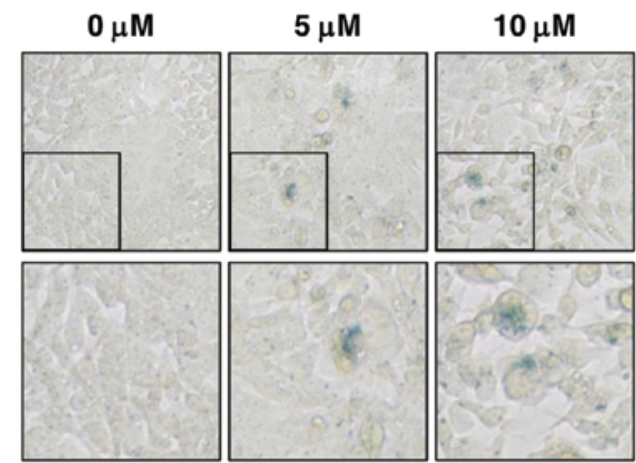

B

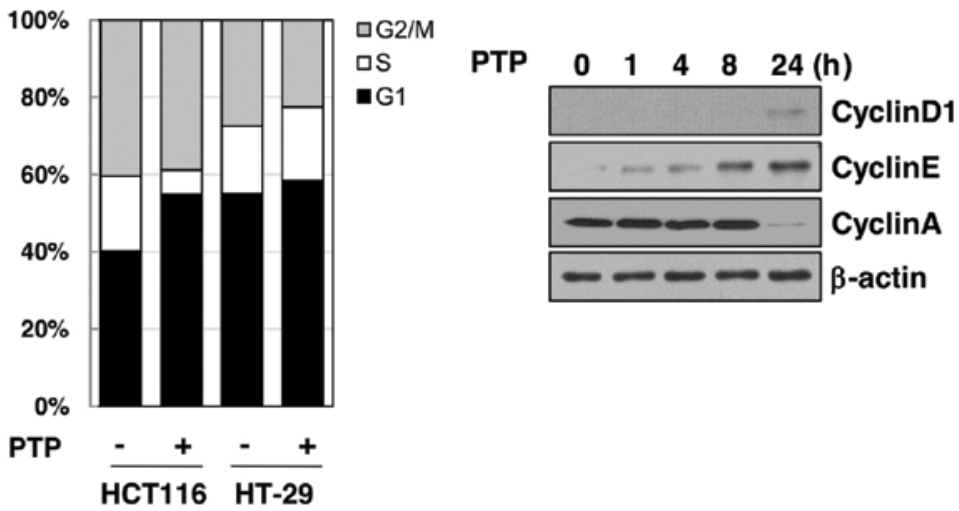

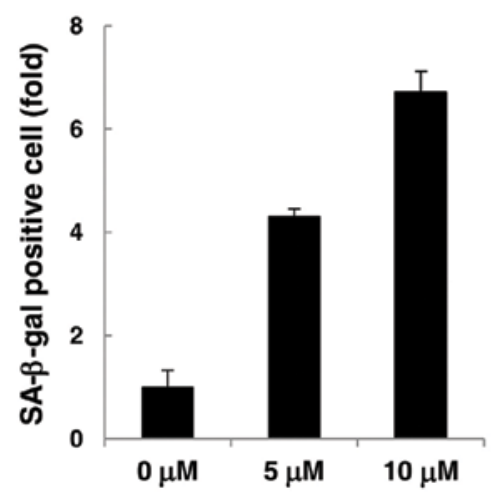

Figure 3. PTP induces G1-phase cell cycle arrest and senescence. (A) HCT116 and HT-29 cells were treated with $10 \mu \mathrm{M}$ PTP for $24 \mathrm{~h}$, and cell cycle distribution was examined by flow cytometry (left panel) and quantitated (right panel). (B) HCT116 cells were treated with $10 \mu \mathrm{M}$ PTP for the indicated times. The levels of cyclin D1 and cyclin E (G1 phase markers), cyclin A (S phase marker) were detected by western blot analysis. $\beta$-actin was used as a loading control. (C) HCT116 cells were treated with 0,5 and $10 \mu \mathrm{M}$ PTP for 6 days. SA $\beta$-galactosidase staining was performed (left panel), and the ratio of the number of positive cells to the number in the untreated control was measured (right panel). Representative images were obtained at x100 magnification.
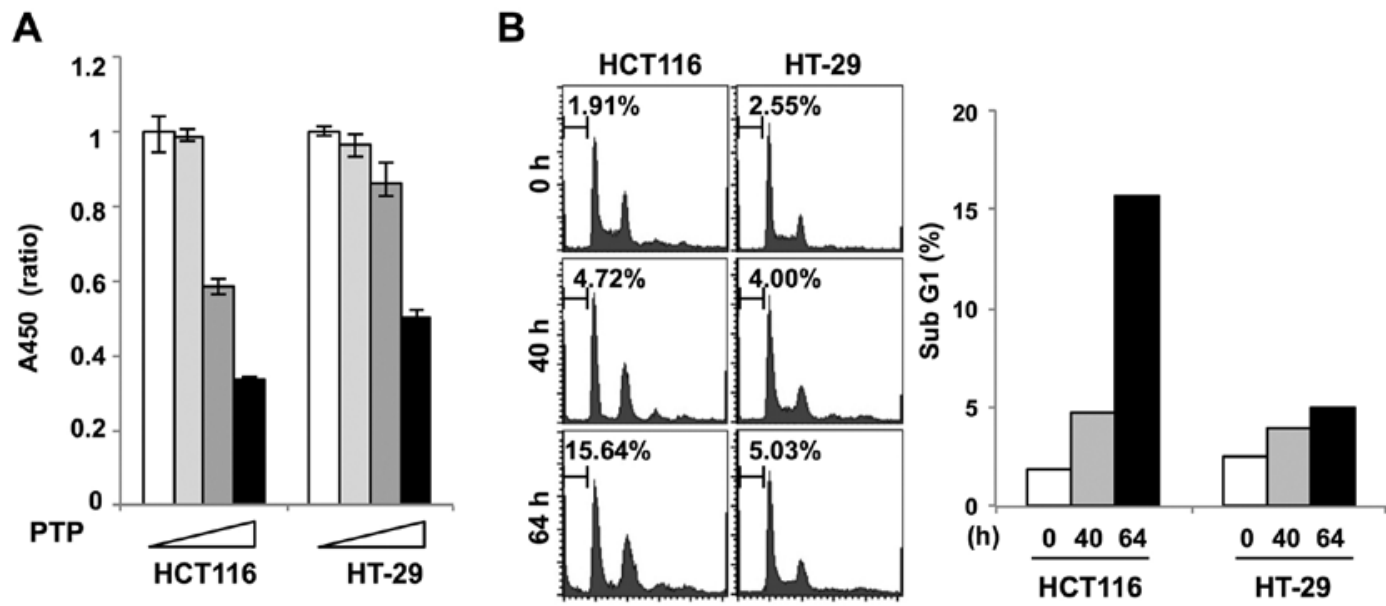

Figure 4. PTP suppresses the proliferation of colon cancer cells. (A) HCT116 and HT-29 cells were treated with $0,2,5$ and $10 \mu \mathrm{M}$ of PTP for 48 h. Cell viability was quantified. (B) HCT116 and HT-29 cells were treated with $10 \mu \mathrm{M}$ PTP for the indicated times, followed by flow cytometric analysis (left panel) and quantitation (right panel) of cell cycle distribution.

western blot analysis, immunofluorescence detection of $\gamma-\mathrm{H} 2 \mathrm{AX}$ foci formation was used to confirm the generation of DNA double-strand breaks (Fig. 5B). The $\gamma$-H2AX foci formation was observed in $\gamma$-irradiated samples (5 Gy, $30 \mathrm{~min}$ ). However, $\gamma$-H2AX foci were not detected in PTP-treated cells. This suggests that PTP does not induce DNA damage and that $\mathrm{p} 53$ phosphorylation by PTP is mediated by protein kinases other than ATM or Chk2. Then, to determine whether PTP enhanced the radiation-induced DNA damage signal, HCT116 cells were pretreated with PTP for $1 \mathrm{~h}$ followed 

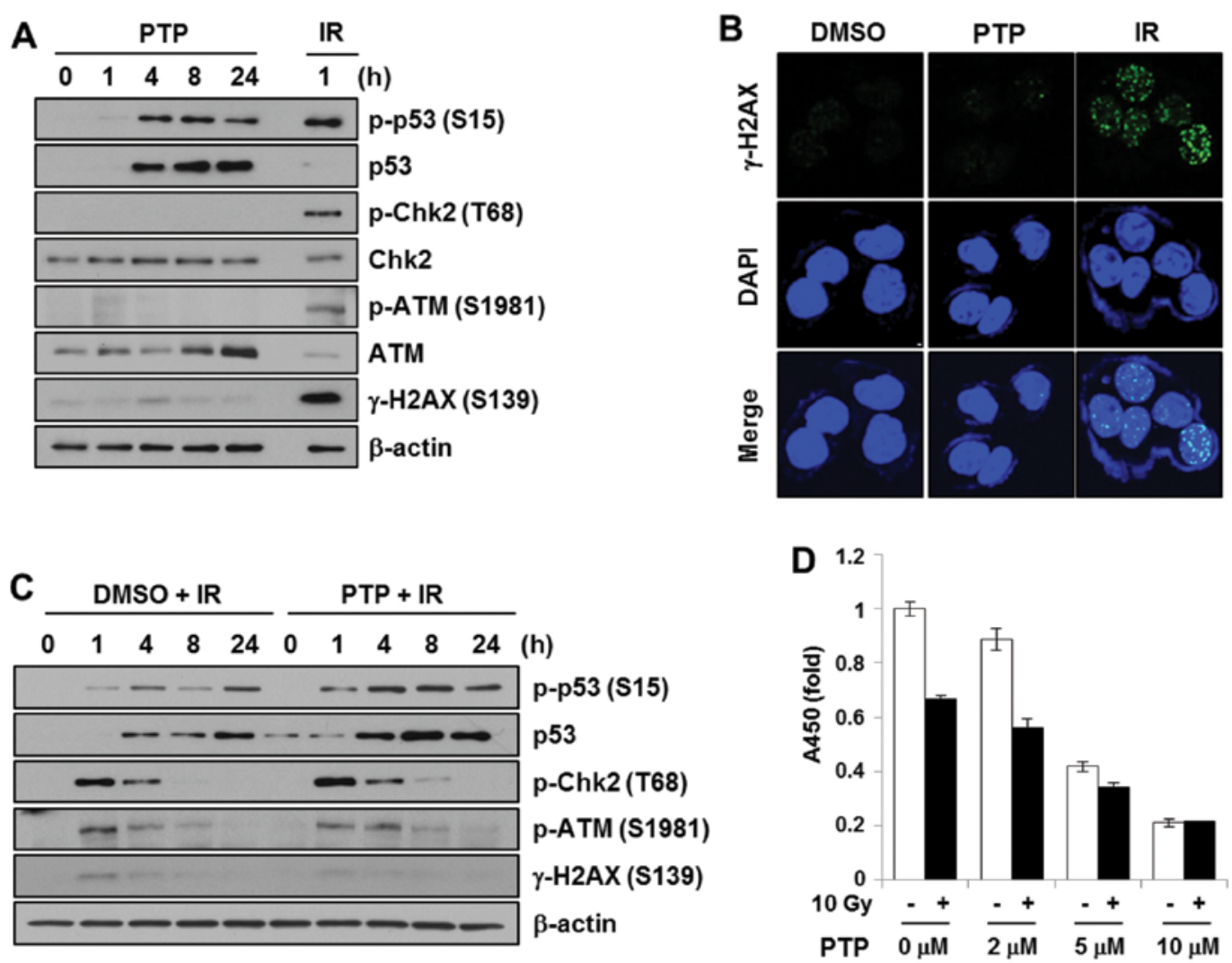

Figure 5. PTP activates p53 in a DNA damage-independent manner. (A) HCT116 cells were treated with $10 \mu \mathrm{M}$ PTP or 5 Gy of $\gamma$-irradiation (IR) for the indicated times followed by protein extraction. Western blot analysis was performed with antibodies that target the indicated proteins in the DNA damage signaling pathway. (B) Generation of DNA damage by PTP $(10 \mu \mathrm{M}$ for $24 \mathrm{~h}$ ) or radiation (IR; $5 \mathrm{~Gy}$, after 30 min) was examined by $\gamma$-H2AX staining. (C) After pretreatment with PTP $(10 \mu \mathrm{M})$ for $1 \mathrm{~h}, \mathrm{HCT} 116$ cells were exposed $5 \mathrm{~Gy}$ of radiation and proteins were extracted at indicated times. Activation of DNA damage signal was confirmed by western blot analysis. (D) After pretreatment with PTP for $16 \mathrm{~h}$, HCT116 cells were exposed to 10 Gy of radiation. Cell viability was evaluated using the Ez-Cytox Cell Viability Assay after $48 \mathrm{~h}$.

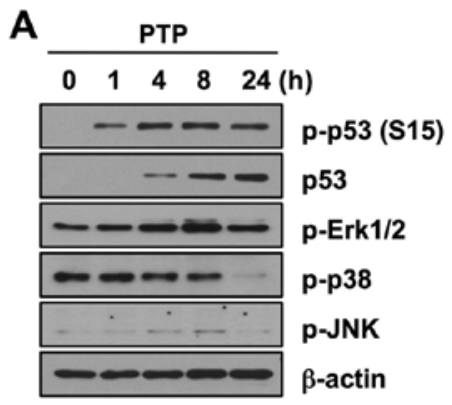

B

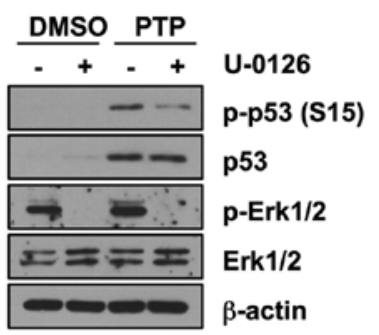

C

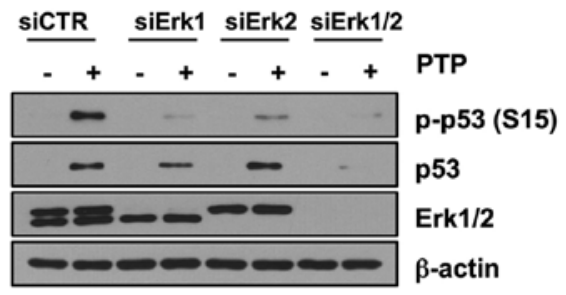

Figure 6. Erk1/2 mediates p53 activation by PTP. (A) HCT116 cells were treated with $10 \mu \mathrm{M}$ PTP and proteins were extracted at indicated times. Western blot analysis was performed with antibodies to detect activation of MAPK signaling. (B) After pretreatment with U-0126 (10 $\mu \mathrm{M})$ for $1 \mathrm{~h}$, HCT116 cells were treated with $10 \mu \mathrm{M}$ PTP for $8 \mathrm{~h}$. (C) After transfection with control siRNA (siCTR) or the indicated targeted siRNAs, HCT116 cells were treated with $10 \mu \mathrm{M}$ PTP for $8 \mathrm{~h}$. The levels of phospho-p53 (Ser15), p53 and Erk1/2 were confirmed by western blot analysis.

by $\gamma$-irradiation. The levels of p53 and phospho-p53 (Ser15) were increased in a time-dependent manner after irradiation. However, pre-treatment with PTP did not cause any significant change in DNA damage signaling (Fig. 5C). Although PTP pre-treatment followed by irradiation induced a higher level of p53 phosphorylation, this might be due to the increased level of $\mathrm{p} 53$ protein by PTP. The effect of PTP pre-treatment on cell proliferation and survival after $\gamma$-irradiation was also investigated. HCT116 cells were pretreated for $16 \mathrm{~h}$ with various concentrations of PTP. Afterwards, 10 Gy of $\gamma$-irradiation was applied. Although the proliferation of HCT116 cells was inhibited by PTP in a dose-dependent manner and by irradiation, cells pretreated with $>5 \mu \mathrm{M}$ PTP did not show further growth inhibition with irradiation (Fig. 5D). This suggests that PTP and $\gamma$-irradiation do not have a synergistic effect on DNA damage signaling or DNA damage-mediated cell death.

PTP induces p53 phosphorylation through activation of Erk1/2. MAP kinases have been shown to phosphorylate wild-type p53 under stress conditions. Therefore, to explore 
A
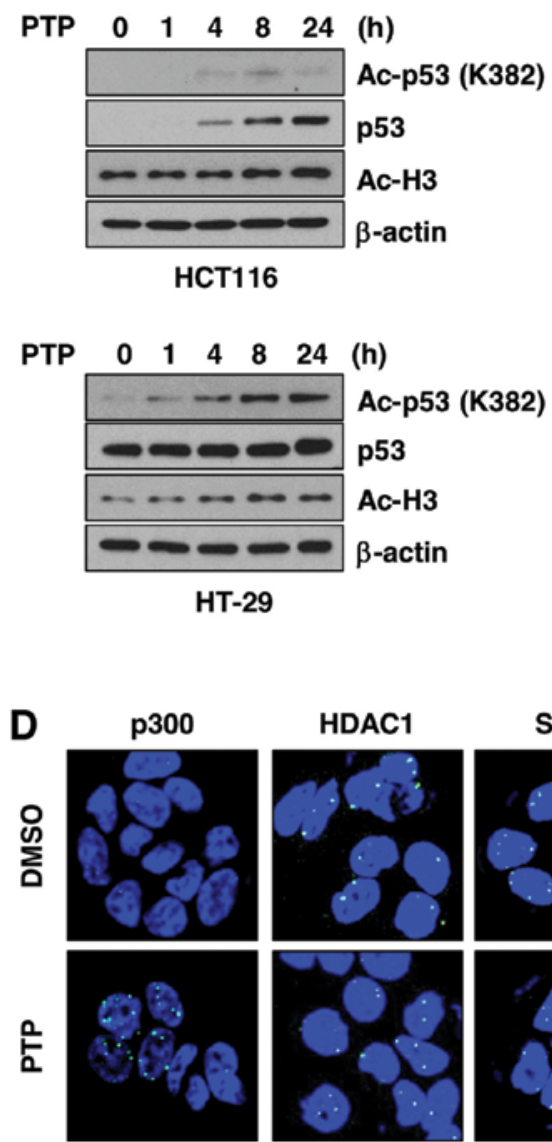

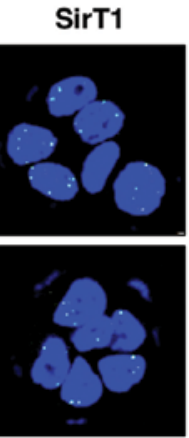

B
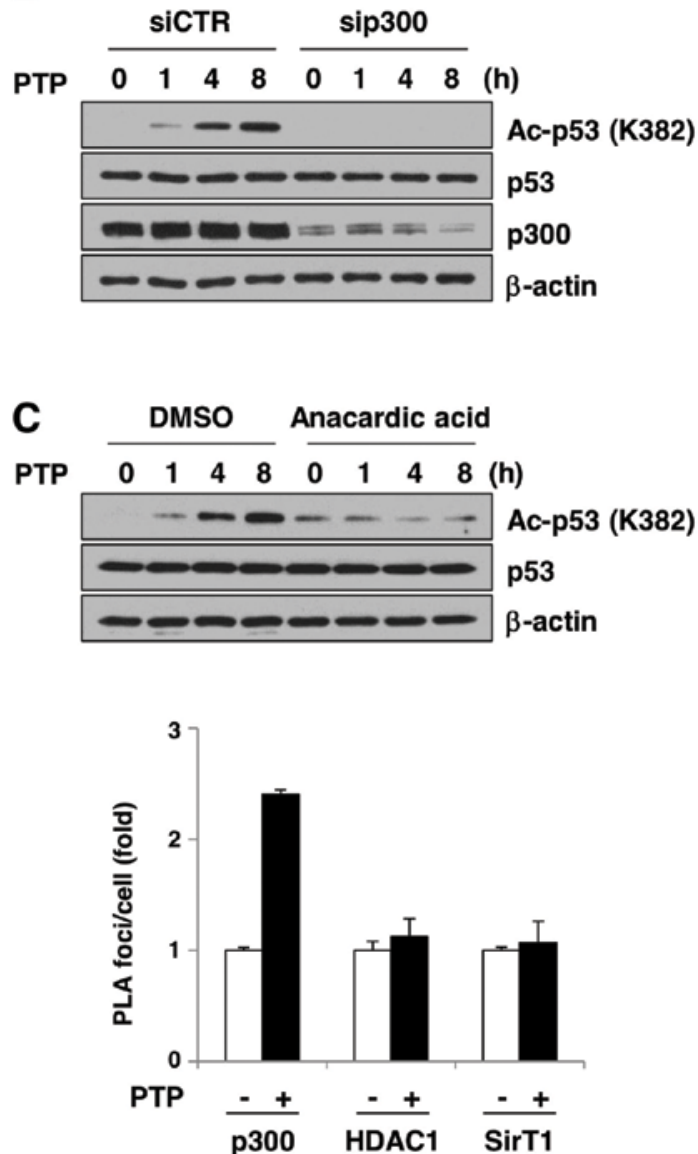

Figure 7. PTP induces acetylation of p53 mediated by recruitment of p300. (A) Levels of acetylated p53 (K382) and histone H3 in PTP-treated HCT116 and HT-29 cells. (B) HCT116 cells were transfected with control siRNA (siCTR) or siRNA targeting p300 (sip300) and then treated with $10 \mu \mathrm{M}$ PTP for the indicated times. (C) HT-29 cells were treated with $10 \mu \mathrm{M}$ PTP for the indicated times in the presence or absence of $10 \mu \mathrm{M}$ of the p300 inhibitor anacardic acid. Proteins extracted from the cells were analyzed by western blot analysis with indicated antibodies. (D) Interactions between p53 and p300, HDAC1, or SIRT1 were confirmed by in situ PLA.

the mechanism of p53 phosphorylation, we first determined whether PTP activates mitogen-activated protein kinases (MAPKs). Of three MAPKs, phosphorylation of Erk1/2 increased in $8 \mathrm{~h}$ (Fig. 6A). However, phosphorylation of other members of the MAPK family, JNK and p38, did not increase. To confirm that Erk1/2 mediates p53 phosphorylation, we investigated the levels of phospho-p53 (Ser15) after PTP treatment in the presence and absence of U-0126, an inhibitor of Erk1/2. Phosphorylation of p53 was inhibited in HCT116 cells treated with $10 \mu \mathrm{M} \mathrm{U}-0126$. However, the total level of p53 protein was not affected by this U-0126 treatment (Fig. 6B). To clarify the contribution of Erk MAPKs on the phosphorylation of p53 by PTP, Erk MAPKs were depleted by siRNA transfection, and then cells were treated with $10 \mu \mathrm{M}$ PTP for $8 \mathrm{~h}$. Both Erk1 and Erk 2 were involved in phosphorylation of p53 at Ser15 (Fig. 6C). Similar to the case with U-0126 treatment, Erk1/2 knockdown affected only the phosphorylation of p53 and not the total level of p53 protein. All these results suggest that PTP induces the phosphorylation of p53 mediated by Erk1/2, but the accumulation of p53 is not caused by modification by Erk1/2.

PTP induces p300-dependent acetylation of $p 53$. A number of groups showed that 553 can be acetylated in vivo in response to a variety of cellular stress signals. p300/CBP and PCAF acetylate $\mathrm{p} 53$ at different sites and increase its stability. To test whether increased p53 level is related to acetylation, we investigated the levels of acetylated p53 in PTP-treated HCT116 and HT-29 cells (Fig. 7A). In the HCT116 and HT-29 cells, acetylation of p53 at Lys382 increased in a time-dependent manner. Interestingly, acetylation of histone $\mathrm{H} 3$ was also increased by PTP. This suggests that PTP affects the activity of histone acetyltransferases and/or HDACs in cells, which leads to acetylation of proteins, including p53. In order to test whether p300 is involved in PTP-induced p53 acetylation, we investigated $\mathrm{p} 53$ acetylation in the presence of $\mathrm{p} 300$ siRNA or an inhibitor of p300. As shown in Fig. 7B, PTP-induced p53 acetylation was completely eliminated in p300-depleted HT-29 cells. Also, PTP-induced p53 acetylation was reduced in HT-29 cells treated with an inhibitor of $\mathrm{p} 300$, anacardic acid (Fig. 7C). To determine if the PTP-mediated p53 acetylation was p300-dependent, we investigated the interaction between p53, p300, and SIRT1 or HDAC1 by in situ PLA. Fig. 7D shows that p53-p300 interaction was induced in PTP-treated HT-29 cells by $\sim 2.4$-fold, based on the number of PLA foci per nucleus compared to DMSO-treated cells. However, p53-SIRT1 and p53-HDAC1 interactions did not significantly change. These results suggest that PTP-induced acetylation of 
p53 is mediated by p300, and not by suppression of SIRT1- or HDAC1-dependent p53 deacetylation.

\section{Discussion}

Although there are recent studies that suggest that p53 may act as a negative regulator of senescence (20), p53 is still considered a key inducer of senescence (2). The tumor suppressor p53 is known to promote arrest in G1-phase of the cell cycle through the induction of p21 expression (21). It has also been reported that the choice between p53-mediated quiescence and senescence is determined by the mTOR pathway in a nutlin-3a-treated melanoma cell line and mouse embryonic fibroblasts (22). In the present study, we show that pyrimidine derivative PTP effectively activates p53 in colorectal cancer cells, which induces p53-dependent cell cycle arrest. Our study provides direct evidence that PTP induced both cell cycle arrest and senescence, showing an enlarged and flattened morphology with SA- $\beta$-gal expression, through activation of p53. Even after removal of PTP, colorectal cancer cells expressing wild-type p53 barely resume their proliferative activity and almost completely lose their capacity to form colonies (data not shown).

It is well established that many cellular stresses lead to phosphorylation of p53 at multiple residues. DNA damage-induced phosphorylation of p53 at Ser15 weakens the association of p53 with MDM2 and leads to accumulation of p53 by preventing MDM2-mediated degradation. We found no evidence that PTP induces DNA damage or activates any canonical DNA damage signaling, measured by phosphorylation of DNA damage signal molecules such as ATM, Chk2 and H2AX (Fig. 5), which raises the possibility that PTP induces p53 phosphorylation in response to stress other than DNA damage. Recently, MAPKs p38 and Erk1/2 have been implicated in phosphorylation of p53 at Ser15 in response to UV irradiation and cisplatin treatment (23-25). We have demonstrated that PTP induces phosphorylation of Erk1/2 in a time-dependent manner and that the patterns of phosphorylation of Erk1/2 are similar to those of p53 (Fig. 6A). Inhibition of Erk1/2 activation (Fig. 6B) and suppression of Erk1/2 expression with siRNA (Fig. 6C) reduces the levels of p53 phosphorylation. Phosphorylation of p53 by PTP was significantly inhibited by knockdown of either Erk1 or Erk2; however, the total p53 level was decreased by only a small amount in Erk2-suppressed cells. This suggests that, whereas Erk1 and 2 both participate in activation of p53 after exposure to PTP, Erk1 appears to play a more important role than Erk2.

Acetylation of p53 is a powerful mechanism of p53 activation. It promotes p53 stabilization through inhibition of the interaction of MDM2 and p53. It also prevents ubiquitination at the same site and recruits cofactors for the promoter-specific activator of p53 transcription activity $(19,26,27)$. Six lysine residues (Lys370, Lys372, Lys373, Lys381, Lys382 and Lys386) in the C-terminal regulatory domain are acetylated by $\mathrm{p} 300 / \mathrm{CBP}$ or PCAF and ubiquitinated by MDM2. We observed that PTP induces acetylation of p53 at Lys382 and of histone $\mathrm{H} 3$ at Lys14 (Fig. 7A). Also, inhibition of p300 mostly reduces the level of PTP-induced p53 acetylation (Fig. 7B and C). Although specific phosphorylation of p53 at residue Ser15 could be one activation step leading to p53-p300/CBP complex formation and subsequent p53 acetylation by p300/CBP, Ser15 phosphorylation is not the only mechanism that can lead to p53 acetylation. Several studies reported that actinomycin $\mathrm{D}$ is also a powerful reagent in inducing p53 acetylation. However, it does not phosphorylate p53 at $\operatorname{Ser} 15(28,29)$. Kuroda et al (30) reported that, when rRNA transcription was suppressed by nucleolar stress, MyBBP1A translocated to the nucleoplasm and promoted p53-p300 interaction to enhance acetylation of p53. However, the mechanism of p53 acetylation without Ser15 phosphorylation is not clear.

Histone deacetylases, HDAC1 and SIRT1 maintain steadystate levels of p53 acetylation $(31,32)$. SIRT1 preferentially deacetylates p53 at Lys382 and reduces the activity of p53 to induce the expression of target genes. Although we did demonstrate that PTP induces the interaction between p53 and p300, the interaction between p53 and HDAC1 or SIRT1 was not changed by exposure to PTP in colorectal cancer cells (Fig. 7D). This shows that PTP-induced p53 acetylation is mediated by increased interaction of p300 with p53, and that PTP may not affect the p53-deacetylating activity of SIRT1 and HDAC1.

In the present study, we have demonstrated that inhibition of tumor proliferation and induction of cellular senescence mediated by activation and accumulation of p53 may be important aspects of the antitumor activity of pyrimidine derivative PTP.

\section{Acknowledgements}

The present study was supported by the National Nuclear R \& D Program of the Ministry of Science, ICT and Future Planning, Republic of Korea (50541-2013).

\section{References}

1. Vousden KH: p53: Death Star. Cell 103: 691-694, 2000.

2. Vogelstein B, Lane D and Levine AJ: Surfing the p53 network. Nature 408: 307-310, 2000.

3. Juven T, Barak Y, Zauberman A, George DL and Oren M: Wild type p53 can mediate sequence-specific transactivation of an internal promoter within the mdm2 gene. Oncogene 8: 3411-3416, 1993.

4. Barak Y, Juven T, Haffner R and Oren M: mdm2 expression is induced by wild type p53 activity. EMBO J 12: 461-468, 1993.

5. Miyashita T, Harigai M, Hanada M and Reed JC: Identification of a p53-dependent negative response element in the bcl-2 gene. Cancer Res 54: 3131-3135, 1994.

6. Banin S, Moyal L, Shieh SY, Anderson CW, Chessa L, Smorodinsky NI, Prives C, Reiss Y, Shiloh Y and Ziv Y: Enhanced phosphorylation of p53 by ATM in response to DNA damage. Science 281: 1674-1677, 1998.

7. Tibbetts RS, Brumbaugh KM, Williams JM, Sarkaria JN, Cliby WA, Shieh SY, Taya Y, Prives C and Abraham RT: A role for ATR in the DNA damage-induced phosphorylation of p53. Genes Dev 13: 152-157, 1999.

8. Bykov VJ, Issaeva N, Shilov A, Hultcrantz M, Pugacheva E, Chumakov P, Bergman J, Wiman KG and Selivanova G: Restoration of the tumor suppressor function to mutant $\mathrm{p} 53$ by a low-molecular-weight compound. Nat Med 8: 282-288, 2002.

9. Miyachi M, Kakazu N, Yagyu S, Katsumi Y, Tsubai-Shimizu S, Kikuchi K, Tsuchiya K, Iehara T and Hosoi H: Restoration of p53 pathway by nutlin-3 induces cell cycle arrest and apoptosis in human rhabdomyosarcoma cells. Clin Cancer Res 15: 4077-4084, 2009.

10. Dai F, Chen Y, Song Y, Huang L, Zhai D, Dong Y, Lai L, Zhang T, Li D, Pang X, Liu M and Yi Z: A natural small molecule Harmine inhibits angiogenesis and suppresses tumour growth through activation of p53 in endothelial cells. PLoS One 7: e52162, 2012. 
11. Zhang Q,Zeng SX,Zhang Y,Zhang Y, Ding D, Ye Q, Meroueh SO and Lu H: A small molecule Inauhzin inhibits SIRT1 activity and suppresses tumour growth through activation of p53. EMBO Mol Med 4: 298-312, 2012.

12. Jain KS, Chitre TS, Miniyar PB, Kathiravan MK, Bendre VS Veer VS, Shahane SR and Shishoo CJ: Biological and medicinal significance of pyrimidines. Curr Sci 90: 793-803, 2006.

13. Zhang N, Ayral-Kaloustian S, Nguyen T, Hernandez R and Beyer C: 2-Cyanoaminopyrimidines as a class of antitumor agents that promote tubulin polymerization. Bioorg Med Chem Lett 17: 3003-3005, 2007

14. Cocco MT, Congiu C, Lilliu V and Onnis V: Synthesis and in vitro antitumoral activity of new hyrazinopyriminide-5-carbonitrile derivatives. Bioorg Med Chem 14: 366-372, 2006.

15. Cocco MT, Congiu C, Lilliu V and Onnis V: Synthesis of new $\mathrm{N}$-(2-(trifluoromethyl)pyridine-yl)anthranilic acid derivatives and their evaluation as anticancer agents. Bioorg Med Chem Lett 14: 5787-5791, 2004.

16. Longley DB, Harkin DP and Johnston PG: 5-Fluorouracil: mechanisms of action and clinical stratagies. Nat Rev Cancer 3 . 330-338, 2003.

17. Lim MJ, Ahn JY, Han Y, Yu CH, Kim MH, Lee SL, Lim DS and Song JY: Acriflavine enhances radiosensitivity of colon cancer cells through endoplasmic reticulum stress-mediated apoptosis. Int J Biochem Cell Biol 44: 1214-1222, 2012.

18. Harris SL and Levine AJ: The p53 pathway: positive and negative feedback loops. Oncogene 24: 2899-2908, 2005.

19. Haupt Y, Maya R, Kazaz A and Oren M: Mdm2 promotes the rapid degradation of p53. Nature 387: 296-299, 1997.

20. Demidenko ZN, Korotchkina LG, Gudkov AV and Blagosklonny MV: Paradoxical suppression of cellular senescence by p53. Proc Natl Acd Sci USA 107: 9660-9664, 2010.

21. Hofseth LJ, Hussain SP and Harris CC: p53: 25 years after its discovery. Trends Pharmacol 25: 177-181, 2004.

22. Korotchkina LG, Leontieva OV, Bukreeva EI, Demidenko ZN, Gudkov AV and Blagosklonny MV: The choice between p53-induced senescence and quiescence is determined in part by the mTOR pathway. Aging (Albany, NY) 2: 344-352, 2010.
23. Melnikova VO, Santamaria AB, Bolshakov SV and Ananthaswamy HN: Mutant p53 is constitutively phosphorylated at Serine 15 in UV-induced mouse skin tumors: involvement of ERK1/2 MAP kinase. Oncogene 22: 5958-5966, 2003.

24. Persons DL, Yazlovitskaya EM and Pelling JC: Effect of extracellular signal-regulated kinase on p53 accumulation in response to cisplatin. J Biol Chem 275: 35778-35785, 2000.

25. She QB, Chen N and Dong Z: ERKs and p38 kinase phosphorylate $\mathrm{p} 53$ protein at serine 15 in response to $\mathrm{UV}$ radiation. J Biol Chem 275: 20444-20449, 2000.

26. Kubbutat MH, Jones SN and Vousden KH: Regulation of p53 stability by Mdm2. Nature 387: 299-303, 1997.

27. Maltzman W and Czyzyk L: UV irradiation stimulates levels of p53 cellular tumor antigen in nontransformed mouse cells. Mol Cell Biol 4: 1689-1694, 1984.

28. Ashcroft M, Taya Y and Vousden KH: Stress signals utilize multiple pathways to stabilize p53. Mol Cell Biol 20: 3224-3233, 2000.

29. Ito A, Lai $\mathrm{CH}$, Zhao X, Saito S, Hamilton MH, Appella E and Yao TP: p300/CBP-mediated p53 acetylation is commonly induced by p53-activating agents and inhibited by MDM2. EMBO J 20: 1331-1340, 2001.

30. KurodaT,Murayama A,Katagiri N,Ohta Y,FujitaE,Masumoto H, Ema M, Takahashi S, Kimura K and Yanagisawa J: RNA content in the nucleolus alters p53 acetylation via MYBBP1A. EMBO J 30: 1054-1066, 2011.

31. Barneda-Zahonero B and Parra M: Histone deacetylases and cancer. Mol Oncol 6: 579-589, 2012.

32. Vaziri H, Dessain SK, Eaton EN, Imai SI, Frye RA, Pandita TK, Guarente L and Weinberg RA: hSIR ${ }^{\text {SIRTI }}$ functions as an NAD-dependent p53 deacetylation. Cell 107: 149-159, 2001. 